\title{
Theories of Poverty: A Critical Review
}

\author{
ALEX ADDAE-KORANKYE
}

CENTRAL BUSINESS SCHOOL, CENTRAL UNIVERSITY, P.O.BOX DS 2310, ACCRA, GHANA.

\begin{abstract}
The study reviewed literature on the theories of poverty. The theories reviewed included theory of individual deficiencies, theory of cultural beliefs, theory of economic, political and social distortions, theory of geographical disparities, and theory of cumulative and cyclical dependencies. The theories were analysed, criticised and measures that will bring the poor out of poverty were recommended. Some of the recommended solutions included: encouraging the poor to embrace self-help strategies, replacing the culture with one that encourages hard work and investment, changing the system for the better, improving infrastructure and local industries competitiveness, and developing comprehensive programmes that will help the poor to be selfsufficient.
\end{abstract}

Key words: Poverty, Cultural beliefs, Individual deficiencies, Geographical disparities, Economic, political, and structural factors, psychological theories, sociological theories.

DOI: $10.7176 / \mathrm{JPID} / 48-08$

\subsection{Introduction}

One of the most prevalent and pervasive social problems in the world today, both developed and developing countries is poverty. In the United States, for example many people live in conditions of poverty or near poverty. According to $\operatorname{Rank}(2004)$, in 2002, an estimated $12.1 \%$ of all people in the United States were considered poor (Rank, 2004). In Africa especially Sub-saharan Africa, the story is even worse, because the number of poor people is increasing according to World Bank(2016).

Poverty according to $\operatorname{JRF}(2013)$ and cited by Davis and Sanchez-Martinez(2014) is a situation where the resources of a person or a group of people in particular material resources are not adequate to meet their minimum needs. The World Bank(2004) and cited by Davis and Sanchez-Martinez(2014) extended the definition further by indicating that poverty is defined as pronounced deprivation in well-being, comprising many dimensions. These dimensions include low incomes, inability to acquire the basic goods and services necessary for survival with dignity, low levels of good health and education, poor access to clean water and sanitation, and inadequate capacity and opportunity to better one's life.

There are a number of theories of poverty which attempt to identify the underlying determinants or causes of poverty Downes (2010). These theories as opined by Shaffer (2008) relate to the lack of or inadequate incentive system to realise an individual's capabilities, the nature of economic underdevelopment, human capital formation, structural elements in the country, the contradictions in capitalism, cultural elements in the society, and geographical location. Blank(2010) is also of the view that the theories of poverty can be classified as economic theories, sociological theories, psychological theories, anthropological theories, and theories of political perspectives. According to Blank(2010) and Jung and Smith(2007), the economic theories of poverty are caused by economic underdevelopment, lack of human capital development, capitalism/ dysfunctional market, social and political forces, individual behavioural characteristics and choices, and welfare dependency or poverty traps. Sociological theories include social stratification theories, housing segregation and persistence of racism, support in the form of social capital, impact of social policies, and impact of values and behaviour(Rank, 2004; Wolf, 2006). Turner and Amanda (2006) assert that psychological theories are caused by language development and accumulated environmental deficits leading to poor academic achievement, intelligence-based psychological theories, manisfestation of moral deficiencies and naturalising perspective. The authors further indicated that, prevalence and incidence of psychiatric disorders (depression, alcoholism, anti-social personality disorders and schizophrenia) and even globalisation are some of the psychological theories on the impact of poverty. In short Turner and Amanda (2006) claim that psychological theories may be broadly classified into two categories; there are those which emphasise the role of the individual and those that emphasise the role of society. In the view of Anthropologists, poverty is caused by culture, globalisation, materialism, and feminism (Frerer, and $\mathrm{Vu}, 2006$ ). There are causes of poverty that also emphasise political science perspectives. These causes include culture, class structure, public policy (the role of the government) and political participation (Morazes and Pintak, 2006). Sameti, et al. (2012) are also of the view that the causes of poverty and hence theories of poverty can be classified under three major headings namely: individual factors, cultural and 
neighbourhood factors, and structural factors. Davis and Sanchez-Martinez (2014) also look at poverty from the economic point of view and pointed out that the economic theories of poverty include Classical theory, Neoclassical theory, Keynesian/Liberal theory and Marxist/radical theory. However, Bradshaw (2006) having reviewed literature on theories of poverty concluded that there are five theories of poverty which include: Poverty caused by individual deficiencies, Poverty caused by cultural belief systems that support sub-cultures of poverty, Poverty caused by economic, political and social distortions or discriminations, Poverty caused by geographical disparities, and Poverty caused by cumulative and cyclical interdependencies.

This paper critically reviews the various theories of poverty and recommends measures to address or tackle the root causes of poverty.

\subsection{Literature Review}

The causes of poverty are numerous but can be grouped under individual factors, cultural factors, structural factors, economic factors, political factors, social factors, geographical factors, cyclical interdependencies among others. This presupposes that the theories of poverty are many, however based on Bradshaw's (2006) assertion this paper categorises all the theories as; individual deficiencies theory, the theory of cultural belief system that support sub-cultures of poverty, economic, political, and social distortions/discrimination theory, geographical theory, and the theory of cumulative and cyclical interdependencies.

\subsection{Theories of poverty}

\subsubsection{The theory of Individual Deficiencies}

This theory of poverty asserts that the individual is responsible for their own poverty situation. Gans, (1995) and cited by Sameti et al (2012) believe that the individual factors that cause or fuel poverty include individual attitude, human capital, and welfare participation. Bradshaw(2006) blame the poor for creating their own problems arguing that with hard work and better choices the poor could have avoided and solved their problems. He further explained that poverty is caused by lack of genetic qualities such as intelligence that are not so easily reversed.

This theory has got its root in American values and belief in the free market system, a system thought to provide opportunity for all. Rank (2004) and cited by Sameti et, al.(2012) asserted that the belief in individualism places much emphasis on individual hard work, and responsibility to acquire basic needs including food, shelter and health care services. Further, the theory based on the premise of American values and belief emphasises that talent, virtue and hard work can lead to success and that individual poverty is an individual failing due to lack of motivation.

The individual theory of poverty is criticised on the grounds that with the emergence of the concept of inherited intelligence in the nineteenth century, the eugenics movement went on to rationalise poverty and even sterilised those who appear to have limited abilities (Bradshaw, 2006). Secondly, Rainwater, (1970) and cited by Bradshaw (2006) beliefs that the poor are afflicted by the mark of Cain; they are meant to suffer, indeed must suffer because of their moral failings.

In the third place a study conducted by Schwartz (2000) and cited by Sameti, et, al.(2012) found that the poor emphasise hard work, dislike welfare system, and personal responsibility. This finding refutes the societal belief that poverty is caused by individual's negative attitude. It is asserted by Asen (2002), and Bradshaw (2006) that any individual can succeed by the application of skills and hard work, and that motivation and persistence are all that is required to achieve success.

\subsubsection{The theory of Cultural Belief Systems that Support Sub-Cultures of Poverty}

This theory focuses on the belief that poverty is created or caused by the transmission over generations of a set of beliefs, values, and skills that are socially generated but individually held (Bradshaw, 2006). Bradshaw(2006) further asserts that individuals are to blame because they are victims of their dysfunctional subculture or culture. It should be noted that this theory has its root in the "Culture of Poverty". The concepts of culture of poverty and social isolation or exclusion provide frameworks that explain how poverty is created and maintained in some neighbourhoods or among some groups. The cultural and environmental factors relate to the influence of people's residential environment that tends to shape poverty or success. The theory of culture of poverty coined 
by Lewis (1966) is built on the assumption that both the poor and the rich have different pattern of values, beliefs, and behavioural norms. This theory argues that the poor are poor because they learn certain psychological behaviours associated with poverty. Lewis (1966) opined that the poor do not learn to study hard, plan the future, have protected sex, or to spend money wisely (Samati et al, 2012). According to Lewis, (1966) and cited by Samati et al.(2012), poverty is transmitted from generation to generation because children are socialised with values and goals associated with poverty. The culture of poverty as asserted by McIntyre (2002) holds that the poor could fight and break away from poverty. Technically according to Bradshaw (2006), the culture of poverty is a subculture of poor people in ghettos, poor regions, or social contexts where they develop a shared set of beliefs, values and norms for behaviour that are separate from but embedded in the culture of the main society.

This theory is criticised by holding the poor responsible for their situation rather than social forces associated with poverty. As argued by Rank(2004), the blame-the -victim ideology used by politicians often focuses on character defects of the poor rather than the primary cause of poverty. Rank(2004) and Darling(2002) believe that human capital can have significant effects on an individual's risk of poverty or success. They further argue that human capital significantly affects people's earnings, and consequently lack of human capital can place an individual at risk of poverty. According to $\operatorname{Rank}(2004)$, and Darling(2002) therefore, individuals with greater human capital are more likely to be competitive in the labour market than those who lack human capital.

Again, the theory of poverty based on perpetuation of cultural values is criticised on the grounds that no one disagrees that the poor have subcultures or that those subcultures of the poor are distinctive and perhaps detrimental. Rather the concern is over the causes and constituents of subculture of poverty (Bradshaw, 2006).

According to Davis and Sanchez-Martinez (2014), the theory is also criticised on the following grounds:

- There is bias in interpretation of observed common attitudes and patterns among groups of poor individuals. This is arguably the principal objection made against this view and rests in the argument that many of the criteria normally used to distinguish the culture of poverty are formulated in terms of western, middle-class values.

- Uncontrolled, individual-oriented research methodology. In empirical studies, the influence upon individuals of values, beliefs and institutions is largely unexamined and even unremarked.

- Inexactness: the boundaries between the sub-culturally poor and the rest of the poor are generally not duly specified, let alone quantified.

- Inconsistency. The concept of sub-culture of poverty cannot be applied when the values and attitudes that are supposed to be inherently possessed by the poor are not accepted by the poor people themselves. By counterargument, the observed attitudes and conditions may well be the result of external causes rather than internal values.

- It is worthy of note that empirical evidence to point to attitudes surrounding education and work as the main drivers behind the choice of going on welfare is still scarce. External factors (environmental and structural) are still believed to play a larger role (Jung and Smith, 2007).

Finally, a significant policy conclusion that applies to classical theories of poverty as Blank(2010) argues, is the result of inherent personal weaknesses or the lack of appropriate behaviour that can be imitated(i.e. poor role models), any policy initiative should always aim at generating a constructive shift in individuals' behaviour. This may involve either supporting activities, ranging from personal counselling and drug rehabilitation to support groups, or threats, in the form of criminal sanctions and punishments. General poverty alleviation (e.g cash transfers) is again, not recommended since it is thought to give rise to incentive problems, thereby encouraging the deleterious habits and dysfunctional behaviour of poor individuals in the first place (Blank, 2010).

\subsubsection{The theory of Economic, Political, and Social Distortions or Discrimination}

To the structural theorists poverty is due to the structure of the larger socioeconomic order Abdulai and Shirmshiry, (2014). Those who believe in this theory attribute the source of poverty to economic, political, and social system which cause people to have limited opportunities and resources with which to achieve income and well-being (Bradshaw, 2006). The same view is expressed by Samati et, al.(2012) who believe that larger economic and social structures is a cause of poverty. They argue that capitalism creates conditions that promote 
poverty, and that irrespective of individuals' effort; (hard work, skills and competencies); the structure of some economies, for instance the economy of United States of America ensures that millions of people are poor. In other words a greater number of literatures suggest that the economic system is structured in such a way that the poor fall behind regardless of how competent they may be (Bradshaw, 2006). The theory also asserts that within a market-based competitive economic system, unequal initial endowments of talents, skills and capital which determine productivity of an individual cause poverty Davis and Sanchez-Martinez (2014).

According to Davis and Moore (1945) and cited by Sameti, et, al.(2012) certain positions in society require special and at times unique talents, skills and knowledge. They further argue that conversion of one's talent into such special skills and knowledge requires a training period during which the individuals undergoing such training must sacrifice their time, money and other resources. People should therefore be motivated accordingly to sacrifice to undergo such training with reward such as higher wages and privileges, otherwise society will suffer. Hurst(2004) cited by Sameti, et, al.2012) opined that the labour-market theories focus on income and earning disparities to explain the major causes of poverty.

The neoclassical labour-market theory assumes that there is relatively free and open market in which the individual can compete for positions and those positions depend on individual's ability, effort and training. According to Grusky(2001) and cited by Sameti, et, al.(2012) the neoclassical labour-market theorists argue that people are rewarded in proportion to what they contribute in society. In addition, they argued that one's education, training, skill and intelligence are very crucial components of productivity in free market society, and that the more a person offers in the free market the greater will be his reward. The neoclassical labour-market theory has been criticised by the dual labour-market theory. The dual labour-market theorists argued that the free market does not work perfectly as proposed by the neoclassical theorists. The dual-market theorists pointed out that other factors in a competitive society tend to determine individual positions and earnings in society. They point out that education and training programmes often fail to reduce inequality and for that matter poverty. Furthermore, it is argued that discrimination against minorities in the labour market works against the effective operation of the free market. The dual-market-theorists also hold the assertion that extensive alienation among workers suggests that the free market model does not work.

Figart and Power (2002), and Blau and Kahn (2000) pointed out that certain features have been identified in the labour market that account for deviation from the general law of labour price determination. One important consideration is the influence of gender and race on labour price. Hurst (2004) documented variations in individual earnings and claimed that these differences are due to social factors such as gender and race. Alkire (2007) supported that view when he noted that differences in human capital accounts partly for the differences in the earning. However, the differential earnings are due to some social factors such as gender and race. There is a connection between labour wage and gender or race, and this is socially constructed. Social constructionist such as Fischer stated that inequality is the result of an intentional construct, created and maintained by social institutions and policies (Sameti, et, al.2012).

Furthermore, certain demographic characteristics including race, gender, work disability, family size and structure, residence, and age are important factors that can increase or decrease the risk of poverty. Generally, poverty rates are higher among single parent household, women, minority groups, households with large number of children, and families (Rank, 2004).

With particular reference to rural poverty, Richardson and London (2007) posited that the relationship between poverty and structural inequities is not accidental or incidental but structural and causal. To solve the problem Richardson and London (2007) strongly suggested that the first thing to be done is to break these barriers to be followed by building rural economies. However, Abdulai and Shamshiry(2014) have made it clear that fighting structural poverty seeks to only strengthen the capacity of the poor to cater for their livelihoods, but not to turn people into passive and permanent beneficiaries of assistance programmes. Abdulai and Shamshiry (2014) believe that the structural theory of poverty has its roots in the Marxist doctrine in which the argument that the existence of low-income class is the creation of the capitalist economic system, or the bourgeoisie, as a strategy for dominance. In assessing this perspective from Islamic perspective, it needs to be clarified that private ownership of property is permissible in Islam. However, such properties must be acquired genuinely. This calls for the interventions of governments largely to provide a level playing ground for the equitable and justifiable wealth acquisition and redistribution (Abdulai and Shamshiry,2014).

\subsubsection{The theory of Geographical Disparities}

This is poverty caused by geographical disparities. Attempts to theorise poverty along the line of geographical disparities led to the emergence of geography of poverty (Abdulai and Shamshiry,(2014). According to 
Bradshaw(2006), this cause of poverty represents rural poverty, ghetto poverty, urban disinvestment, southern poverty, third -world poverty, and others that exist separate from other theories. This theory of poverty calls attention to the fact that people, institutions, and cultures in certain areas lack the objective resources needed to generate well-being and income, and that they lack the power to claim redistribution.

According to Abdulai and Shamshiry (2014) the use of geographical disparities in poverty analysis presupposes the concentration of poverty in some particular areas, communities, localities within countries and among regions in the world. Some explanations given about the factors responsible for poverty include disinvestment, proximity to natural resources, density, diffusion of innovation and other factors. It has long since become a conventional belief that advantaged areas stand to grow more than disadvantaged areas even in periods of general economic growth. Solutions suggested to deal with poverty associated with geographical disparities favoured tackling the main factors that precipitate decline in depressed areas (Abdulai and Shamshiry, 2014).

Abdulai and Shamshiry(2014) opined that the proximity of poverty conditions creates widespread poverty. The attraction of businesses and firms away from other locations to particular locations presupposes the likely impoverishment of the 'other locations'. For example, low housing prices in such impoverished locations may attract more poor people, thereby leading to housing disinvestment by building owners. Bradshaw (2006) asserts that the fact that poverty is more intense in certain places than others is old, and explanations abound in the development literature about why some regions lack economic resources to compete. Some of the reasons he gave for the disparities in poverty include disinvestment, proximity to natural resources, density, diffusion of innovation, amongst others.

According to Bradshaw (2006), there are three perspectives of this theory. One theoretical perspective on spatial concentrations of poverty comes from economic agglomeration theory, the second from central place theory, and last but not the least involves selective out-migration. Economic agglomeration theory explains how proximity or concentration of similar firms attracts supportive services and markets, which further attracts more firms. Conversely, where there is poverty and poverty conditions it generates more poverty. Central place theory asserts that advantaged areas tend to grow faster than disadvantage areas even in periods of general economic growth and that there will be multiplier effect but not equalising according to classical economists. Selective outmigration perspective according to Wilson(2003) and cited by Bradshaw (2006) holds that the people from ghetto areas with the highest levels of education, the greatest skills, widest world view, and most extensive opportunities were the ones who migrated out of the central city locations to other places. In addition he argued that these departing people also were the community's best role model and were often civic leaders. Rural poverty according to Bradshaw (2006) is similar to selective out-migration.

\subsubsection{The theory of Cumulative and Cyclical Interdependencies}

According to Abdulai and Shamshiry, (2014) this theory of poverty is also called the Cyclical Theory of Poverty. This kind of poverty occurs when individuals or households are suddenly unable to provide for their necessities due to unforeseen circumstances, like natural disasters. The cyclical explanation clearly looks at individual situations and community resources as mutually dependent, with faltering economy, for example, creating individuals who lack resources to participate in the economy, which makes economic survival even harder for the community since people pay fewer taxes (Bradshaw, 2006). He continues to explain that inadequate employment leads to inadequate income causing inadequate spending, consumption, and savings. This presupposes that individuals cannot invest in training, businesses or start their own businesses; which further means that there will be no expansion, market will dwindle, people will disinvest, leading to lack of opportunities in the community.

The second level of the cycle has to do with health challenges. There will also be health issues or challenges, due to inability to afford preventive medicine, a good diet, and a healthy living environment. All these are some of the reasons why the poor falls behind. Further, the cycle of poverty also means that due to inadequate income the poor fail to invest in their children's education, the children learn in poor quality schools and fall further behind when they go to the job market. They are also vulnerable to illness and poor medical care.

The third level of the cycle of poverty is due to the lack of jobs and incomes, there will be worsening selfconfidence, weak motivation, and depression. The psychological problems of individuals are aggravated by their association with other individuals, leading to a culture of despair. In the rural areas this culture of despair affects leaders as well, leading to a sense of hopelessness and fatalism among community leaders (Bradshaw, 2006). 


\subsection{Methodology}

This research was purely a critical review of existing literature. It reviewed the various literatures on theories of poverty, critically analysed each theory, and pointed out the challenges, limitations or flaws in each of the theories. The study concluded by proposing solutions or recommendations for the poor to come out of poverty.

\subsection{Conclusion and Recommendations}

As asserted by Ghatak (2014), there are two schools of thought of poverty dimensions. There are those who believe that in terms of their potential, the poor is just like the non-poor and simply operate within a tighter choice set. To such people, poverty results when individuals operate within an unfavourable external environment, e.g poor governance, inadequate infrastructure e.t.c.

On the other hand, there are others who hold the view that even when there are no unfavourable external factors or frictions, the poor are subject to different pressures and constraints from the non-poor which push them to make choices that worsen their poverty levels. A number of recommendations are suggested to minimise if not entirely eliminate poverty.

First, if the poverty is as a result of individual deficiencies, it is recommended that self-help strategies should be employed to push the poor out of poverty. This may include elimination of various forms of assistance given to the poor so that the poor will be forced to work. However, it is suggested that the policy should allow the disabled, elderly, and the children to still enjoy the assistance as is happening in Ghana under the government's Livelihood Empowerment Against Poverty (LEAP) programme.

Secondly, if the poverty is as a result of cultural beliefs; it is recommended that society replaces the culture with one that encourages productive work, investment, and social responsibility. If the culture of poverty produces opportunistic and non-productive subculture that is perpetuated over generations, then educational programmes should be designed to provide alternative socialisation for the next generation to reduce poverty. Another strategy to overcome poverty caused by culture is to redefine culturally appropriate strategies to improve the group's well-being. For instance the society can encourage the formation of cooperatives to help each other come out of poverty.

Thirdly, if poverty is caused by distortions in the economic, political, and social systems, the solution is to change that particular system. To help change the system some questions that need to be asked and addressed include the following: How can one get more jobs, improve schooling for the poor, bridge the inequality gap, remove discrimination bias from housing, banking, education, and employment and ensure equal political participation by poor persons? To address the above questions and hence minimise the poverty challenge, there must be social movement at the grassroots level to exert pressures on vulnerable parts of the system and to force social change. For example, government is advised to support the development of micro, small, and medium enterprises (MSMEs). The government and development partners can grant loans to MSMEs at concessionary rates, offer them training and capacity building, offer them technical advice, etc. Another recommendation is to create alternative innovative institutions which have the desire to help the poor improve their standard of living. For example, in Ghana the establishment of National Board for small scale industries(NBSSI), Rural and Community banks, Microfinance Institutions, etc have assisted and continue to assist the promotion and development of micro, small, and medium enterprises(MSMEs), providing housing, schooling, empowering women, etc. Further, there must be social policies deliberately aimed at reducing poverty, such as creating employment, increasing wages and salaries, expanding safety net, etc. For example the creation of Nation Builders Corps(NABCO) in Ghana.

In the fourth place, poverty caused by geographical disparities can be solved by improving local industry competiveness, investment in infrastructure including water, waste disposal, school, and other public facilities; establishment of affordable housing, instituting tax based incentive programmes for economic development and channelling private investment, among others.

The last but not the least; if the poverty is caused by cumulative and cyclical interdependencies, the strategies should be to help the poor achieve self-sufficiency. These may include developing comprehensive programmes, collaboration with other organisations to provide complementary services, and community organising. Specifically strategies should help the poor create income and economic assets, provide education and skills, 
provide access to health care and other needed social services, build close personal ties as well as networks to others, help the poor become resourceful, and improve their leadership as well as community organising skills.

In summary, it can be said that since the causes of poverty are highly complex, care must be taken to determine the most appropriate measures to tackle it. These interventions or measures may be numerous and varied. For instance Austin (2006) suggested that those on public assistance requires a number of support services or interventions to transition to workforce as indicated above. Secondly, programmes design for the youth including adolescents and teenage mothers should concentrate more on positive attitudes towards work and education. Thirdly, welfare programmes which include training and childcare should be encouraged in such a way that the youth will be motivated to participate. In addition to these, there should be high quality early childhood programmes which will provide good evidence for long term social benefits.

Furthermore, poverty reduction intervention programmes should be conscious of the impact of race, gender, and geography on the ability of the poor to find jobs. Policies should also be formulated to encourage poor families organise themselves to advocate for constructive anti-poverty interventions. It is also recommended that antipoverty policies should be mindful of development of human capital, developing their skills to enable the poor find jobs or create their own jobs. Again, more residential mobility programmes should be provided to reduce poverty rates among inner city minority population to help them relocate, especially if the cause of poverty is traceable to geography.

\section{References}

Abdulai, A.M., and E. Shamshiry (2014) Theory and Practice on the Nexus between Poverty, Natural Resources and Governance. Springer Link.

Alkire, S. (2007) Choosing dimensions: The capability approach and multidimensional poverty. CPRC Working Paper, 88, 1-25.

Asen, R. (2002) Visions of Poverty: Welfare Policy and Political Imagination. East Lansing: Michigan State University Press.

Austin, M.J.(2006). Understanding poverty from multiple social science perspectives. University of California, USA.

Blank, R. (2010) "Selecting among anti-poverty measures, can an economist be both critical and caring?", Review of Social Economy, 61, 447-469.

Blau, F. \& Kahn, M. (2000) Gender differences in pay. The Journal of Economic Perspectives, 14 (4), 75-99.

Bradshaw, T.K.(2006) Theories of Poverty and Anti-Poverty Programs in Community Development. Rural Poverty Research Centre (RPRC) Working Series No.06-05 Oregon State University and University of Missouri.

Darling, R. (2002) Partnership models in human services: Sociological foundations and practices. New York, NY: Kluwer Academic/ Plenum Publisher.

Davis, P.; Sanchez-Martinez M., (2014) A review of the economic theories of poverty, National Institute and Social Research. Discussion Paper, No. 435.

Downes, A. (2010) Poverty and its Reduction in the Small Developing Countries of the Caribbean. Paper presented at Conference on "Ten Years of "War Against Poverty", Chronic Poverty Research Centre, University of Manchester, United Kingdom, September 8-10.

Figart, M. \& Power, M. (2002) Living wages, equal wage: Gender and labor market policies in the United States: New York, NY: Routledge.

Frerer, K. and Catherine $\mathrm{Vu}(2006)$. An Anthropological view of poverty. University of California, USA.

Ghatak M.(2014) Theories of poverty traps and Anti-poverty policies. London School of Economics

Hurst, C. (2004) Social inequality: Forms, causes and consequences. New York, NY: Pearson Education Inc. 
Jung, S. Y., and Smith, R. (2007) "The economics of poverty: Explanatory theories to inform practice", Journal of Human Behavior in the Social Environment, 16(1-2), 21-39.

Lewis, O.(1966) The Culture of Poverty. Vilnus University Journals; Vol 215. No. 4 pp 1-25.

McIntyre, L. (2002) The practical skeptic: Core concepts in sociology. Mountain View,CA: Mayfield Publishing Co.

Morazes, J. and Pintak, Indira(2006). Political perspectives on poverty. University of California, USA.

Rank, M. R., Yoon, H., \& Hirschl, T. A. (2003). American poverty as a structural failing: Evidence and arguments. Journal of Sociology and Social Welfare, 30(4), 3-29.

Rank, M. (2004) One nation underprivileged: Why American poverty affects us all. New York, NY: Oxford Press.

Richardson, J.A., and London, J.K.(2007) Strategies and Lessons for Reducing Persistent Rural Poverty: A Social-Justice Approach to Funding Rural Community Transformation. Journal of Community Development Society; Vol 38, No.1.

Sameti, M., Esfahani, R.D., and Haghighi, H. K. (2012). Theories of Poverty: A Comparative Analysis, Kuwait Chapter of Arabian Journal of Business and Management Review ; Vol. 1, No.6.

Shaffer, P.(2008) "New Thinking on Poverty: Implications for Globalisation and PovertyReduction Strategies". Real World Economic Review; Issue 47.

Turner, K , and Amanda, L(2006). Psychological theories of poverty. University of California, USA.

Wolf, J.P (2006). Sociological theories of poverty in urban America. University of California, USA.

World Bank(2016). Poverty in rising Africa; Africa Poverty Report, Washington, D.C, USA. 